\title{
Análise quanti-qualitativa da arborização urbana de uma avenida em uma cidade da região Amazônica
}

A vegetação em via pública caracteriza a identidade cultural e climática do local, oferecendo diversos benefícios, como conforto térmico ocasionado pela sombra parede acústica devido à densidade no local e consequentemente o melhoramento da qualidade do ar, fatores que devem estar sempre presentes em um planejamento urbano. Objetivou-se com o presente trabalho a realização de inventário quantitativo e qualitativo do patrimônio vegetativo da Avenida Mendonça Furtado. Na análise quantitativa foram quantificados o número total de indivíduos, densidade, frequência, dominância, diâmetro, altura total e comprimento de copa. Já na análise qualitativa foram avaliados a viabilidade das espécies, qualidade do fuste, fitossanidade, densidade de copa, superficialidade das raízes, presença de fiação elétrica e local de inserção dos indivíduos. No inventário foram verificados 776 indivíduos, pertencentes a 27 famílias, 45 gêneros e 50 espécies. A espécie Handroanthus serratifolius (ipê amarelo) obteve o número mais expressivo de representantes, seguido da espécie Ixora chinensis (ixora vermelha) e Mangifera indica (mangueira) que, juntas, representaram $53,35 \%$ da vegetação. De forma geral, a vegetação urbana da avenida apresentou um elevado nível de diversidade de espécies, porém mal distribuídas no local.

\section{Quanti-qualitative analysis of urban forestation of an avenue in a city in the Amazon region}

\begin{abstract}
The vegetation in public roads characterizes the cultural and climatic identity of the place, offering several benefits, such as thermal comfort provided by tree shadows, acoustic wall due to the density in the place and consequently the improvement of air quality, elements that should always be present in urban planning The objective of this study was to carry out a quantitative and qualitative inventory of vegetative heritage of Mendonça Furtado Avenue. In the quantitative analysis the total number of individuals, density, frequency, dominance, diameter, total height and crown length were quantified. As for the qualitative analysis, the species viability, stem quality, plant health, crown density, root superficiality, presence of electric wiring and place of insertion of individuals were evaluated. In the inventory 776 individuals, from 27 families, 45 genera and 50 species were verified. The Handroanthus serratifolius (yellow Ipê) species obtained the most significant number of representatives, followed by Ixora chinensis (red ixora) and Mangifera indica (mango tree) which, together accounted for $53,35 \%$ of the vegetation. In general, the urban vegetation of the avenue presented a high level of species diversity, however poorly distributed in the area.
\end{abstract}

Keywords: Quantitative Analysis; Urban Planning; Urban Vegetation.

Topic: Planejamento, Gestão e Políticas Públicas Ambientais Reviewed anonymously in the process of blind peer.
Received: 05/10/2019

Approved: 22/11/2019
Rodrigo Alex Alves dos Santos (iD

Universidade Federal do Oeste do Pará, Brasil

http://lattes.cnpq.br/7199088275192844

http://orcid.org/0000-0003-3247-1934

santos sjk@hotmail.com

Cristina Aledi Felsemburgh (iD

Universidade Federal do Oeste do Pará, Brasil

http://lattes.cnpq.br/8446110971099607

http://orcid.org/0000-0002-8199-8639

crisalefel@gmail.com

Andressa Jaqueline Viana de Souza (iD

Universidade Federal do Oeste do Pará, Brasil

http://lattes.cnpq.br/1941608083658085

http://orcid.org/0000-0002-3632-124X

andressa-viana8@hotmail.com

\author{
Ana Kaira Canté da Conceição (iD \\ Universidade Federal do Oeste do Pará, Brasil \\ http://lattes.cnpq.br/0359544394358895 \\ http://orcid.org/0000-0003-2288-1622 \\ anakaira17@gmail.com \\ Ádria Giselle dos Santos Lira (iD) \\ Universidade Federal do Oeste do Pará, Brasil \\ http://lattes.cnpq.br/0436951094856886 \\ http://orcid.org/0000-0002-9711-624X \\ liraadria971@gmail.com

\section{Vanessa Leão Peleja (iD)} \\ Universidade Federal do Oeste do Pará, Brasil \\ http://lattes.cnpq.br/4847354203016902 \\ http://orcid.org/0000-0003-2138-3277 \\ peleja.floresta@gmail.com
}

Referencing this:

SANTOS, R. A. A.; FELSEMBURGH, C. A.; SOUZA, A. J. V.; CONCEIÇÃO, A. K. C.; LIRA, A. G. S.; PELEJA, V. L.. Análise quanti-qualitativa da arborização urbana de uma avenida em uma cidade da região Amazônica. Nature and Conservation, v.12, n.3, p.64-78, 2019. DOI: http://doi.org/10.6008/CBPC2318-2881.2019.003.0007 


\section{INTRODUÇÃO}

O crescimento urbano acelerado e desordenado de uma cidade acarreta a criação de novos bairros sem planejamento adequado, ocasionando o surgimento de muitos conflitos urbanos, dentre eles, os problemas com o componente vegetal urbano (PARRY et al., 2012). A vegetação urbana desempenha funções essenciais e diversas nos centros urbanos, dentre as quais podemos citar a influência no conforto térmico do ambiente urbano através da produção de sombra, amenizando a temperatura, o aumento do teor de oxigênio e de umidade, a absorção de gás carbônico, além de influenciar na qualidade do ar atuando como filtro de poluentes, operar como barreiras acústicas, melhorar as condições do solo e caracterizar a beleza natural dos ambientes urbanos (MELO et al., 2007). O planejamento urbano é um procedimento vital em um aglomerado populacional tendo influência direta nos inúmeros benefícios ambientais e sociais que auxiliam na qualidade de vida nas cidades e também na saúde mental da população (CECCHETTO et al., 2014; RANSAN et al., 2015).

Entretanto, em muitas situações o planejamento urbano deixa de incluir a arborização urbana devidamente planejada, a falta de diretrizes para a arborização urbana permite que as iniciativas particulares pontuais e desprovidas de conhecimento técnico tomem espaço com plantios irregulares de espécies sem compatibilidade com o local (ALMEIDA et al., 2010). Neste contexto é importante a atuação da gestão pública por meio de orientações à população através da educação ambiental, de implantação, manejo e manutenção da arborização urbana, abordando temáticas como podas mal executadas e os danos causados nas árvores, assim como os benefícios gerados pela vegetação urbana (VELOPE-FILIK et al., 2007).

A vegetação em áreas urbanas é indispensável para o desenvolvimento urbano e irá requerer o conhecimento da situação existente, através de inventário quantitativo e qualitativo, assim como o conhecimento das características das espécies que poderão ser utilizadas (COLETTO et al., 2008). O planejamento do plantio de espécies de plantas em áreas urbanas deve incluir também um plano de monitoramento e manutenção dessas áreas, de modo que os serviços ambientais prestados pela vegetação urbana sejam contínuos e não venham a se tornar transtornos à população (SANTOS et al., 2015). Objetivouse com o presente trabalho realizar o inventário quantitativo e qualitativo da arborização ao longo da Avenida Mendonça Furtado, na cidade de Santarém, oeste do estado do Pará.

\section{MATERIAIS E MÉTODOS}

\section{Área de estudo}

A avaliação foi realizada na área urbana de Santarém que está inserida na mesorregião do Baixo Amazonas no estado do Pará - Brasil, sob as coordenadas geográficas 0225'30"S e 5442'50"W (DOURADO et al., 2017). O município tem uma área da unidade territorial referentes ao ano de 2018 de $22.887,080 \mathrm{~km}^{2}$, possuindo uma população estimada em 2018 de 302.667 habitantes, com uma densidade demográfica de 16,91 hab/km² (IBGE, 2019). De acordo com a classificação de Koppen, o tipo climático da região é Ami, correspondendo a um clima tropical chuvoso, onde o mês mais frio tem temperatura média superior a $18^{\circ} \mathrm{C}$ 
e precipitação pluvial anual oscilando em torno de $2.000 \mathrm{~mm}$ (SANTOS et al., 2014).

A Avenida Mendonça Furtado foi escolhida por ser uma das vias de maior fluxo em Santarém, e por conter muitos empreendimentos nos mais diversos setores, como educação, economia, lazer, saúde e moradia, com 4,8 km de extensão e $15 \mathrm{~m}$ de largura aproximadamente em seus quarteirões, estando entre as vias, Alameda Final no bairro do Mapiri e na junção da Avenida Dom Frederico Costa e a Rua do Imperador, no Bairro da Prainha. Além destes, a Avenida Mendonça Furtado, integra outros bairros como Santa Clara, Aldeia, Fátima e Laguinho.

As coletas e análises foram realizadas no período de março de 2017 a abril de 2018 e as parcelas foram delimitadas pelos quarteirões ao longo de toda a extensão da avenida. Os critérios para avaliação foram obtidos com o inventário total, realizado na avenida, por meio da identificação botânica e análises quantitativa e qualitativa.

\section{Identificação botânica}

Foi realizado o levantamento total do componente vegetativo da avenida, no qual os indivíduos foram enumerados com a utilização de um rotulador digital. Os rótulos foram colocados nos indivíduos em ordem crescente no sentido Mapiri-Prainha para posterior identificação. A identificação taxonômica foi realizada in loco e quando necessário foi realizada a coleta do material botânico para comparação com material depositado no Herbário da Universidade Federal do Oeste do Pará (UFOPA) e em consultas aos herbários virtuais do REFLORA (Jardim Botânico do Rio de Janeiro - JBRJ) e do Instituto Nacional de Ciência e Tecnologia (INCT).

A partir da identificação, as plantas foram classificadas de acordo com sua origem, em nativas (N) ou exóticas (E) do Brasil, mediante consulta realizada na Lista de Espécies da Flora do Brasil e W3 Tropicos. A classificação foi realizada de acordo com o Sistema de Classificação Angiosperm Phylogeny Group - APG III (2009).

\section{Análise quantitativa}

Para obtenção de maiores informações sobre a comunidade de plantas da avenida e com base no inventário, foram calculados, de acordo com (ROMANI et al., 2012 ; BRIANEZI et al., 2013) o número total de indivíduos (NTI), densidade absoluta (DA), densidade relativa (DR), frequência absoluta ( $F A)$, frequência relativa (FR), dominância absoluta (DoA), dominância relativa (DoR), altura total $(\mathrm{Ht})$, diâmetro a altura do peito (DAP) - para os hábitos árvores, arvoretas e palmeiras e comprimento de copa (CC) - para os hábitos árvores, arvoretas, palmeiras, arbustos e subarbustos).

\section{Análise qualitativa}

Para as análises qualitativas considerou-se: Viabilidade das espécies (VE): este parâmetro foi analisado para verificar se a espécie possuía algum dano em sua estrutura dendrológica, no fuste, copa ou na superficialidade da raiz, sendo condicionada em 6 categorias: ausente - quando não existiu nenhum dano; 
leve - quando existiu danos mas não expressou relevância; moderado - quando existiu danos, mas podem ser reparáveis; grave - quando os danos gerados podem levar ao declínio do indivíduo; cortada - quando o indivíduo foi retirado, mas ainda apresenta o tronco; ou morta - quando o indivíduo estava seco ou em morte iminente.

Fitossanidade (FT): foi observado se o indivíduo apresentava em seu fuste e na superficialidade da raiz a presença de fungos, formigas, cupins, ervas-daninha, brocas ou se estava saudável, estabelecendo os seguintes parâmetros: ausente - quando o indivíduo estava saudável; leve - quando apresentou a ocorrência de algum dos citados, mas sem danos ao indivíduo; moderado - quando apresentou ocorrência, danificando o indivíduo, mas sendo reversível; e grave - quando apresentou a ocorrência, danificando o indivíduo de maneira irreversível.

Qualidade do fuste (QF): os hábitos árvore e arvoreta com DAP $\geq 15 \mathrm{~cm}$ foram considerados para esta avaliação, classificando-os em: cilíndrico - quando o fuste não apresentou nenhuma tortuosidade; levemente tortuoso - quando o fuste apresentou tortuosidade, mas de maneira pouco expressiva; tortuoso - quando o fuste apresentou tortuosidade expressiva; e ramificado - quando o fuste apresentou ramificações abaixo de $2 \mathrm{~m}$, não ramificando na base.

Densidade da copa (DC): os hábitos árvore, arvoreta, palmeira, arbusto e subarbusto foram considerados e para esta observação, foram utilizadas quatro categorias: rala - quando a copa apresentou pouca densidade, realizando pouco sombreamento; moderada - quando a copa foi densa, mas apresentou espaços em sua cobertura, permitindo a passagem de luz; densa - quando a copa foi densa, não possuindo nenhum espaço que permitiu a passagem de luz; e ausente - quando não apresentou copa.

Superficialidade das raízes (SR): este parâmetro foi classificado em: leve - quando existiram pequenas fissuras geradas pelo crescimento das raízes; moderada - quando apresentou ondulações significativas no local de inserção provocando fissuras; grave - quando a presença das raízes impediu o tráfego de veículos ou pedestres; ou ausentes - quando as raízes não interferiram no local.

Condições de contato com fiação elétrica (FE) e telefônica (FT): foi analisado o posicionamento de todos os indivíduos em relação à fiação elétrica (FE) e telefônica (FT) da avenida, sendo classificado, como: presente - quando existiu contato; potencial - na iminência de existir contato; ou ausente - quando não existiu contato.

Local de inserção (니): analisou-se o local onde estavam inseridos os indivíduos na avenida, como no canteiro central, praças, calçadas ou na via de rolamento.

Estrutura do local de inserção (ELI): parâmetro que foi utilizado para analisar a estrutura de inserção onde cada indivíduo estava inserido, estando classificado em: ausente - quando não existiu estrutura; e presente - quando existiu algum tipo de estrutura como, canteiros, vasos, pneus etc.

\section{RESULTADOS}

\section{Análise quantitativa}


Ao longo de toda a sua extensão na avenida foram inventariados um total de 776 indivíduos, sendo divididos de acordo com o hábito em 272 árvores, 112 arvoretas, 16 palmeiras, 99 arbustos, 117 subarbustos, 95 herbáceas, 4 lianas e 39 mudas, além de 8 indivíduos cortados, apenas com a presença do tronco e 14 indivíduos mortos e/ou morreram durante o período avaliado (tabela 1).

Tabela 1: Identificação botânica e número de indivíduos na Avenida Mendonça Furtado.

\begin{tabular}{|c|c|c|c|c|}
\hline Família & Nome científico & Nome vulgar & $\begin{array}{c}\text { № de } \\
\text { indivíduos }\end{array}$ & Origem \\
\hline \multirow[t]{3}{*}{ AGAVACEAE } & Agave angustifolia Haw. & Pinteira-do-caribe & 40 & Exótica \\
\hline & Agave sp. & Agave & 2 & - \\
\hline & Agave desmettiana 'Joe Hoak' & Agave & 37 & Exótica \\
\hline \multirow[t]{2}{*}{ ANACARDIACEAE } & Anacardium occidentale L. & Cajueiro & 7 & Nativa \\
\hline & Mangifera indica $\mathrm{L}$. & Mangueira & 119 & Exótica \\
\hline \multirow[t]{3}{*}{ APOCYNACEAE } & Allamanda cathartica $\mathrm{L}$. & Alamanda amarela & 29 & Nativa \\
\hline & Allamanda blanchetii A. DC. & Alamanda roxa & 1 & Nativa \\
\hline & Plumeria pudica Jacq. & Buquê-de-noiva & 10 & Exótica \\
\hline \multirow[t]{5}{*}{ ARECACEAE } & Euterpe olaracea Mart. & Açaí & 3 & Nativa \\
\hline & Cocos nucifera $\mathrm{L}$. & Coqueiro & 3 & Nativa \\
\hline & Roystonea oleracea (N.J. Jacquim) O.F.Cook. & Palmeira imperial & 4 & Exótica \\
\hline & Washingtonia filifera $\mathrm{H}$. Wendl. & Palmeira leque & 3 & Exótica \\
\hline & Bactris spp. & Palmeira (NID) & 7 & - \\
\hline BALSAMINACEAE & Impatiens parviflora DC. & $\begin{array}{l}\text { Maria-sem- } \\
\text { vergonha }\end{array}$ & 3 & Exótica \\
\hline \multirow[t]{6}{*}{ BIGNONIACEAE } & Crescentia amazonica Ducke. & Cuieira & 9 & Nativa \\
\hline & Handroanthus serratifolius (Vahl) S. Grose. & Ipê amarelo & 175 & Nativa \\
\hline & Handroanthus pulcherrimus (Sandwith) Mattos. & Ipê da praia & 6 & Nativa \\
\hline & Handroanthus heptaphyllus (Vell.) Mattos. & Ipê rosa & 4 & Nativa \\
\hline & Tecoma stans var. stans (L.) Juss. ex Kunth. & Ipê de jardim & 1 & Exótica \\
\hline & Handroanthus spp. & Ipê (NID) & 7 & - \\
\hline CACTACEAE & $\begin{array}{l}\text { Cereus jamacaru subsp. calcirupicola (F.Ritter) N.P.Taylor \& } \\
\text { Zappi }\end{array}$ & Mandacaru & 2 & Nativa \\
\hline CHRYSOBALANACEAE & Licania tomentosa (Benth.) Fritsch. & Oiti & 13 & Nativa \\
\hline COMBRETACEAE & Terminalia catappa $\mathrm{L}$. & Castanholeira & 5 & Exótica \\
\hline COSTACEAE & Costus spicatus (Jacq.) Sw. & Cana-do-brejo & 1 & Nativa \\
\hline COMMELINACEAE & Tradescantia pallida (Rose) D.R. Hunt. & Trapoeraba-roxa & 3 & Exótica \\
\hline CICADACEAE & Cycas revoluta Thunb. & Palmeira cica & 3 & Exótica \\
\hline DAVALLIACEAE & Nephrolepis sp. & Samambaia & 1 & - \\
\hline \multirow[t]{2}{*}{ EUPHORBIACEAE } & Ricinus communis var. brasiliensis Müll. Arg. in Mart. & Carrapateira & 1 & Exótica \\
\hline & Jatropha gossypiifolia var. elegans (Pohl) Mull. Arg. & Pinhão-roxo & 2 & Nativa \\
\hline \multirow{3}{*}{$\begin{array}{l}\text { FABACEAE } \\
\text { CAELSAPINIACEAE }\end{array}$} & Hymenaea courbaril L. & Jatobá & 2 & Nativa \\
\hline & $\begin{array}{l}\text { Senna macranthera var. macranthera (DC. ex Collad.) Irwin \& } \\
\text { Barneby }\end{array}$ & Pau-fava & 2 & Nativa \\
\hline & Tamarindus indica $\mathrm{L}$. & Tamarindo & 1 & Nativa \\
\hline FABACEAE MIMOSACEAE & Vachellia farnesiana Wight \& Arn & Acássia amarela & 2 & Nativa \\
\hline \multirow[t]{4}{*}{ FABACEAE PAPILIONACEAE } & Andira inermis subsp. glabricalyx R.T. Penn. & Alvineira & 5 & Nativa \\
\hline & Clitoria fairchildiana R. A. Howard & Palheteira & 1 & Nativa \\
\hline & Erythrina variegata $\mathrm{L}$. & Brasileirinho & 1 & Exótica \\
\hline & Tipuana tipu (Benth.) Kuntze & Amendoin-acássia & 1 & Exótica \\
\hline LAMIACEAE & Clerodendrum thomsonae Balf. & Trepadeira & 4 & Exótica \\
\hline LECYTHIDACEAE & Lecythis pisonis subsp. pisonis Cambess. & Sapucaia & 7 & Nativa \\
\hline LYTHRACEAE & Lagerstroemia indica $\mathrm{L}$. & Resedá & 4 & Exótica \\
\hline MALPIGHIACEAE & Byrsonima crassifolia (L.) Kunth. & Muricizeiro & 1 & Nativa \\
\hline MALVACEAE & Hibiscus rosa-sinensis var. minor L. & Papoula & 2 & Nativa \\
\hline MELIACEAE & Azadirachta indica A. Juss. & $\mathrm{Nim}$ & 26 & Exótica \\
\hline MORACEAE & Ficus catappifolia Kunth \& Bouch. & Figueira & 12 & Nativa \\
\hline \multirow[t]{2}{*}{ MYRTACEAE } & Psidium guajava $\mathrm{L}$. & Goiabeira & 3 & Nativa \\
\hline & Syzygium malaccense (L.) Merr. \& L. M. Perr. & Jambeiro & 7 & Exótica \\
\hline OLEACEAE & Jasminum sp. & Jasmim & 1 & - \\
\hline PORTULACACEAE & Portulaca grandiflora Hook. & Onze horas & 3 & Nativa \\
\hline \multirow[t]{5}{*}{ RUBIACEAE } & Palicourea marcgravii var. pubescens A.St.-Hil. & Erva de rato & 1 & Nativa \\
\hline & Ixora coccinea Linn. & Ixora amarela & 36 & Exótica \\
\hline & Ixora finlaysoniana Wall. ex G.Don. & Ixora branca & 1 & Exótica \\
\hline & Ixora undulata Roxb. & Ixora rosa & 1 & Exótica \\
\hline & Ixora chinensis Lam. & Ixora vermelha & 120 & Exótica \\
\hline \multirow[t]{2}{*}{ RUTACEAE } & Citrus aurantifolia (Christm.) Swingle & Laranja-da-terra & 1 & Exótica \\
\hline & Citrus jambhiri Lush. & Limão rugoso & 1 & Exótica \\
\hline NÃO IDENTIFICADAS & - & - & 29 & - \\
\hline
\end{tabular}


Com a identificação botânica os indivíduos foram agrupados em 27 famílias, 45 gêneros e 50 espécies. Foram identificados a nível de gênero 5 espécimes e 29 indivíduos não foram identificados. As 5 famílias com maior número de espécies foram: Fabaceae (8), Bignoniaceae (6), Rubiaceae (5) e Arecaceae (5). Dentre as espécies identificadas 26 são nativas e 24 são exóticas.

A espécie com o maior número de indivíduos foi Handroanthus serratifolius (175), seguido da espécie Ixora chinensis (120), Mangifera indica (119), Agave angustifolia (40) e Agave desmettiana (37). Os maiores valores de densidade absoluta e relativa foram encontrados para as espécies Handroanthus serratifolius ( $D A=20,97 ; D R=20,68)$, Mangifera indica ( $D A=15,15 ; D R=14,94)$, Agave angustifolia ( $D A=11,69 ; D R=11,53)$ e Ixora chinensis (DA=10,65; $\mathrm{DR}=10,50)$ (tabela 2).

Para frequência absoluta e relativa os maiores valores foram encontrados para as espécies Handroanthus serratifolius ( $F A=75,86 ; F R=10,33)$, Mangifera indica ( $F A=72,41 ; F R=9,86)$, Ixora chinensis ( $F A=37,93 ; F R=5,16)$ e Agave angustifolia ( $F A=24,14 ; F R=3,29)$ (tabela 2). Para dominância, as espécies arbóreas que apresentaram maior uniformidade na distribuição de seus indivíduos na via foram Mangifera indica (DoA=1,6399), Ficus catappifolia (DoA=0,5601), Handroanthus serratifolius ( $D \circ A=0,4143$ ), Terminalia catappa (DoA=0,2536) e Syzygium malaccense ( $D \circ A=0,0399)$. Estas cinco espécies representaram 88,09\% da dominância relativa de toda vegetação da avenida (tabela 2).

Tabela 2: Componentes da estrutura horizontal da Avenida Mendonça Furtado.

\begin{tabular}{|c|c|c|c|c|c|c|c|}
\hline Nome Cintífico & $\mathbf{N}$ & DA & DR (\%) & FA & FR (\%) & DoA & DoR (\%) \\
\hline Mangifera indica & 119 & 15,15 & 14,94 & 72,41 & 9,86 & 1,6399 & 49,68 \\
\hline Ficus catappifolia & 12 & 3,73 & 3,67 & 24,14 & 3,29 & 0,5601 & 16,97 \\
\hline Handroanthus serratifolius & 175 & 20,97 & 20,68 & 75,86 & 10,33 & 0,4143 & 12,55 \\
\hline Terminalia catappa & 5 & 1,20 & 1,19 & 10,34 & 1,41 & 0,2536 & 7,68 \\
\hline Handroanthus spp. & 7 & 1,27 & 1,25 & 13,79 & 1,88 & 0,1094 & 3,32 \\
\hline Syzygium malaccense & 7 & 1,24 & 1,22 & 17,24 & 2,35 & 0,0399 & 1,21 \\
\hline Lecythis pisonis & 7 & 0,06 & 0,05 & 10,34 & 1,41 & 0,0383 & 1,09 \\
\hline Vachellia farnesiana & 2 & 0,56 & 0,55 & 6,90 & 0,94 & 0,0357 & 1,08 \\
\hline Licania tomentosa & 13 & 2,04 & 2,01 & 20,69 & 2,82 & 0,0316 & 0,96 \\
\hline Senna macranthera & 2 & 0,21 & 0,21 & 3,45 & 0,47 & 0,0309 & 0,94 \\
\hline Não identificada & 29 & 2,84 & 2,80 & 41,38 & 5,63 & 0,0245 & 0,74 \\
\hline Crescentia amazônica & 9 & 2,56 & 2,53 & 17,24 & 2,35 & 0,0224 & 0,68 \\
\hline Handroanthus pulcherrimu & 6 & 0,61 & 0,60 & 10,34 & 1,41 & 0,0218 & 0,66 \\
\hline Azadirachta indica & 26 & 0,97 & 0,96 & 37,93 & 5,16 & 0,0127 & 0,38 \\
\hline Clitoria fairchildiana & 1 & 0,48 & 0,47 & 3,45 & 0,47 & 0,0110 & 0,33 \\
\hline Bactris spp. & 7 & 1,25 & 1,23 & 17,24 & 2,35 & 0,0110 & 0,33 \\
\hline Washingtonia filifera & 3 & 0,20 & 0,19 & 6,90 & 0,94 & 0,0091 & 0,28 \\
\hline Anacardium occidentale & 7 & 0,39 & 0,38 & 17,24 & 2,35 & 0,009 & 0,26 \\
\hline Citrus aurantifolia & 1 & 0,48 & 0,47 & 3,45 & 0,47 & 0,0046 & 0,14 \\
\hline Cycas revoluta & 3 & 0,00 & 0,00 & 6,90 & 0,94 & 0,0045 & 0,13 \\
\hline Erythrina variegata & 1 & 0,05 & 0,05 & 3,45 & 0,47 & 0,0035 & 0,10 \\
\hline Andira inermis & 5 & 0,31 & 0,31 & 10,34 & 1,41 & 0,0033 & 0,10 \\
\hline Cocos nucifera & 3 & 0,14 & 0,14 & 6,90 & 0,94 & 0,0029 & 0,09 \\
\hline Handroanthus heptaphyllus & 4 & 1,29 & 1,27 & 6,90 & 0,94 & 0,0029 & 0,09 \\
\hline Hymenaea courbaril & 2 & 0,17 & 0,17 & 6,90 & 0,94 & 0,0021 & 0,06 \\
\hline Euterpe olaracea & 3 & 0,68 & 0,68 & 6,90 & 0,94 & 0,0019 & 0,06 \\
\hline Byrsonima crassifólia & 1 & 0,05 & 0,05 & 3,45 & 0,47 & 0,0011 & 0,03 \\
\hline Tamarindus indica & 1 & 0,05 & 0,05 & 3,45 & 0,47 & 0,0008 & 0,02 \\
\hline Psidium guajava & 3 & 0,14 & 0,14 & 6,90 & 0,94 & 0,0004 & 0,01 \\
\hline Tipuana tipu & 1 & 0,05 & 0,05 & 3,45 & 0,47 & 0,0003 & 0,01 \\
\hline Agave angustifolia & 40 & 11,69 & 11,53 & 24,14 & 3,29 & - & - \\
\hline Agave sp. & 2 & 0,19 & 0,19 & 6,90 & 0,94 & - & - \\
\hline Agave desmettiana & 37 & 3,43 & 3,39 & 34,48 & 4,69 & - & - \\
\hline Allamanda catártica & 29 & 2,36 & 2,33 & 13,79 & 1,88 & - & - \\
\hline Allamanda blanchetii & 1 & 0,48 & 0,47 & 3,45 & 0,47 & - & - \\
\hline Plumeria pudica & 10 & 0,77 & 0,76 & 20,69 & 2,82 & - & - \\
\hline Cereus jamacaru & 3 & 0,34 & 0,33 & 3,45 & 0,47 & - & - \\
\hline
\end{tabular}




\begin{tabular}{|c|c|c|c|c|c|c|c|}
\hline Costus spicatus & 1 & 0,10 & 0,10 & 3,45 & 0,47 & - & - \\
\hline Ricinus communis. & 1 & 0,13 & 0,13 & 3,45 & 0,47 & - & - \\
\hline Palicourea marcgravii & 1 & 0,10 & 0,10 & 3,45 & 0,47 & - & - \\
\hline Tecoma stans var. stans & 1 & 0,05 & 0,05 & 3,45 & 0,47 & - & - \\
\hline Ixora coccínea & 36 & 3,13 & 3,09 & 27,59 & 3,76 & - & - \\
\hline Ixora finlaysoniana & 1 & 0,05 & 0,05 & 3,45 & 0,47 & - & - \\
\hline Ixora undulata & 1 & 0,08 & 0,08 & 3,45 & 0,47 & - & - \\
\hline Ixora chinensis & 120 & 10,65 & 10,50 & 37,93 & 5,16 & - & - \\
\hline Tradescantia pallida & 3 & 0,29 & 0,29 & 6,90 & 0,94 & - & - \\
\hline Jasminum sp. & 1 & 0,48 & 0,47 & 3,45 & 0,47 & - & - \\
\hline Citrus jambhiri & 1 & 0,48 & 0,47 & 3,45 & 0,47 & - & - \\
\hline Lagerstroemia indica & 4 & 1,90 & 1,88 & 6,90 & 0,94 & - & - \\
\hline Impatiens parviflora & 3 & 0,63 & 0,62 & 10,34 & 1,41 & - & - \\
\hline Portulaca grandiflora & 3 & 0,48 & 0,47 & 6,90 & 0,94 & - & - \\
\hline Roystonea oleracea & 3 & 1,00 & 0,98 & 10,34 & 1,41 & - & - \\
\hline Hibiscus rosa-sinensis & 2 & 0,56 & 0,55 & 6,90 & 0,94 & - & - \\
\hline Jatropha gossypiifolia & 2 & 0,95 & 0,94 & 3,45 & 0,47 & - & - \\
\hline Nephrolepis exaltata & 1 & 0,10 & 0,10 & 3,45 & 0,47 & - & - \\
\hline Clerodendrum thomsonae & 4 & 1,90 & 1,88 & 3,45 & 0,47 & - & - \\
\hline TOTAL & 776 & 101,4 & 100,02 & 734,48 & 100,00 & 3,3008 & 100,00 \\
\hline
\end{tabular}

$\mathrm{N}$ - Quantidade de indivíduos; DA - Densidade Absoluta; DR - Densidade Relativa; FA - Frequência Absoluta; FR Frequência Relativa; DoA - Dominância Absoluta; e DoR: Dominância Relativa

De acordo com o hábito dos indivíduos as alturas médias encontradas foram de 8,56 $\mathrm{m}$ para árvores, 1,76 $\mathrm{m}$ para arvoretas, $3,87 \mathrm{~m}$ para palmeiras, $1,44 \mathrm{~m}$ para arbustos, $0,73 \mathrm{~m}$ para subarbustos, $0,99 \mathrm{~m}$ para herbáceas e 3,18 para lianas (tabela 3). Os cinco indivíduos que apresentaram maior altura média estimada foram a Terminalia catappa (9,08 m), Ficus catappifolia (8,57 m), Vachellia farnesiana (8,45 m), Mangifera indica $(7,77 \mathrm{~m})$ e Byrsonima crassifolia $(7,10 \mathrm{~m})$. Ao avaliar o DAP dos indivíduos em relação ao tipo de hábito, o hábito árvore obteve o maior valor $(15,37 \mathrm{~cm})$, seguido por arvoreta $(9,41 \mathrm{~cm})$ e palmeira $(7,01 \mathrm{~cm})($ tabela 3).

No comprimento da copa foram considerados somente os hábitos árvore, arvoreta, palmeira, arbusto e subarbusto, representando 711 dos 776 indivíduos do censo. Observou-se que a espécie com maior comprimento de copa foi Mangifera indica $\left(18,5 \mathrm{~m}^{2}\right)$, Ficus catappifolia $\left(11,8 \mathrm{~m}^{2}\right)$, Terminalia catappa $(10,7$ $\left.\mathrm{m}^{2}\right)$, Vachellia farnesiana $\left(9,9 \mathrm{~m}^{2}\right)$ e Lecythis pisonis $\left(9,9 \mathrm{~m}^{2}\right)$.

As árvores obtiveram em média $4,78 \mathrm{~m}^{2}$ de comprimento de copa, representando $35 \%$ da cobertura vegetal da avenida, seguida pelas arvoretas $\left(2,93 \mathrm{~m}^{2}\right) 14,56 \%$ e palmeiras $\left(3,31 \mathrm{~m}^{2}\right)$, correspondendo a $1,93 \%$. Arbustos e subarbustos apresentaram comprimento de copa de $1,43 \mathrm{~m}^{2}$ e $0,90 \mathrm{~m}^{2}$ respectivamente e constituem $27,86 \%$ do componente vegetativo da área de estudo (tabela 3 ).

Tabela 3: Altura, diâmetro e comprimento da copa de acordo com o hábito das plantas

\begin{tabular}{|l|l|l|l|l|}
\hline Hábito & N & Ht méd $\mathbf{( m )}$ & DAP méd $(\mathbf{c m})$ & CC méd $\left(\mathbf{m}^{\mathbf{2}}\right)$ \\
\hline Árvores & 272 & $8,56 \pm 2,90$ & $19,41 \pm 15,37$ & $4,78 \pm 3,21$ \\
\hline Arvoretas & 112 & $1,76 \pm 1,24$ & $10,79 \pm 9,41$ & $2,93 \pm 2,11$ \\
\hline Palmeiras & 16 & $3,87 \pm 2,73$ & $7,26 \pm 7,01$ & $3,31 \pm 2,09$ \\
\hline Arbustos & 99 & $1,44 \pm 0,85$ & - & $1,43 \pm 0,77$ \\
\hline Subarbustos & 117 & $0,73 \pm 0,21$ & - & $0,90 \pm 0,34$ \\
\hline Herbáceas & 95 & $0,99 \pm 0,94$ & - & - \\
\hline Lianas & 4 & $3,18 \pm 1,11$ & - & - \\
\hline
\end{tabular}

$\mathrm{N}$ - número de indivíduos; Ht méd $(\mathrm{m})$ - altura média; DAP med $(\mathrm{m})$ - Diâmetro médio a altura do peito; e CC méd Média do comprimento da copa.

\section{Análise qualitativa}

Em relação a viabilidade das plantas avaliadas, 47 indivíduos foram avaliados como saudáveis, não 
apresentando nenhuma alteração em sua estrutura sendo considerado como ausente, 659 sofreram algum dano na copa, fuste ou superficialidade da raiz, sendo caracterizado como leve por não causar nenhum agravo ao indivíduo, 38 apresentaram danos moderados, mas sendo possível a reparação, 10 foram classificados como grave, pois os danos aparentes levaram ao declínio dos indivíduos, 8 foram cortados apresentando o tronco no local e 14 estavam mortos (aspecto seco) ou em morte iminente (figura $1 \mathrm{~A}$ ).

As espécies que apresentaram situação de declínio ou morte iminente foram: Handroanthus serratifolius (3), Mangifera indica (2), Terminalia catappa (1), Roystonea oleracea (1); Ficus catappifolia (1), Tamarindus indica (1) e Citrus aurantifolia (1). Para fitossanidade foram considerados todos os 776 indivíduos inventariados, dentre os quais, 434 não apresentaram nenhuma alteração em sua estrutura, classificado como ausente, 62 foram classificados como alteração leve, apresentando formigas, mas não ocasionando danos ao indivúduo, 189 em caráter moderado, apresentando cupins e fungos no fuste, danificando a estrutura de maneira reversível e 91 como graves, por apresentarem na estrutura fungos, formigas, cupins e devido aos danos, apresentaram podridão parcial do fuste ou de galhos, sendo irreversível (figura 1B).

Para qualidade do fuste, foram consideradas apenas as árvores e arvoretas, representando 385 dos 776 indivíduos do inventário, sendo classificados com fuste cilíndrico (24), com tortuosidade pouco expressiva (123), com tortuosidade em caráter expressivo (147) e com ramificação antes $2 \mathrm{~m}$ de altura em relação ao solo (91) (figura 1C).

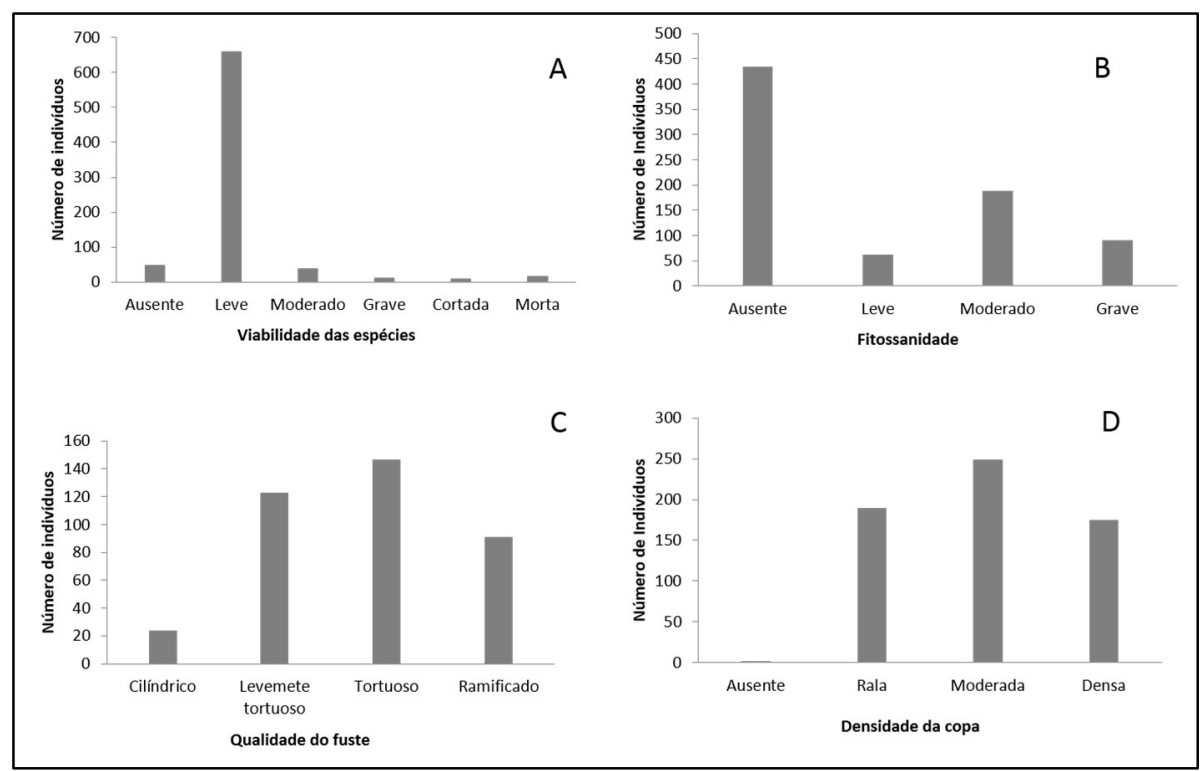

Figura 1: Número de indivíduos e viabilidade das espécies (A), fitossanidade (B), qualidade do fuste (C) e densidade de copa (DC).

Para a análise da densidade da copa (figura 1D), foram considerados, árvore, arvoreta, palmeira, arbusto e subarbusto, representando 616 do total de indivíduos avaliados. Observou-se 2 indivíduos que não apresentaram copa sendo constituídos apenas de fuste, 190 possuíam copa rala com pouca densidade, acarretando na geração de pouco sombreamento; 249 indivíduos apresentaram copas moderadas, com densidade significativa mas permitindo a passagem de luz em vários pontos e 175 apresentaram copa altamente adensada, totalmente fechada, limitando ao mínimo a passagem de luz.

Com relação à superficialidade das raízes foram observados todos os indivíduos em relação ao nível 
de agressão com o meio, constatando-se que: ausente - 673 não provocaram nenhum dano em seu entorno; leve - 54 provocaram fissuras não significativas que pudessem intervir no fluxo da avenida; moderado - 36 provocaram fissuras que desnivelaram a via, danificando seu entorno; e grave - 13 indivíduos ocasionaram danos que podem dificultar o fluxo de veículos e pedestres no local (figura 2A). Neste contexto, destacam-se as espécies, Mangifera indica, Ficus catappifolia e Terminalia catappa sendo as principais causadoras dos transtornos, por suas extensas e volumosas raízes.

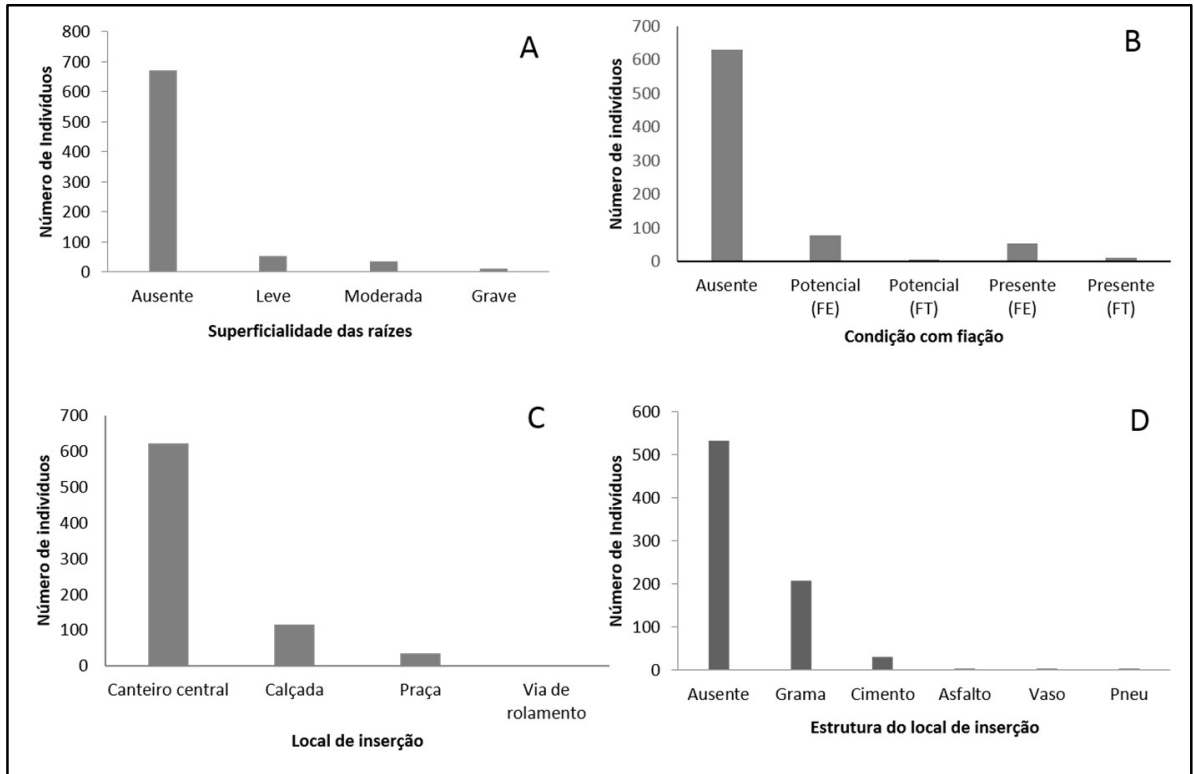

Figura 2: Número de indivíduos e superficialidade das raízes (A), condição com fiação (B), local de inserção (C) e estrutura do local de inserção (D).

Avaliando a condição de contato ou potencial com fiação elétrica (FE) e telefônica (FT), constatou-se que: ausentes - 631 plantas não apresentaram presença e nem potencialidade com a fiação elétrica ou telefônica; potencial - 76 ofereceram potencialidade de contato com a fiação elétrica e 4 com a fiação telefônica; e presente - 54 indivíduos apresentaram contato com a fiação elétrica e 11 com a fiação telefônica (figura 2B).

Quanto ao local de inserção, foi verificado que 622 indivíduos estão situados no canteiro central da avenida (80,15\%), 115 na calçada, 36 distribuídos em praças e 3 na via de rolamento (figura 2C). Inseridas no canteiro central, destacam-se as espécies Handroanthus serratifolius e Mangifera indica correspondendo a $37,89 \%$ do levantamento total de indivíduos, e a $44,37 \%$ das espécies localizadas no canteiro central da avenida. Já nas calçadas, observou-se a ocorrência das espécies Terminalia catappa e Ficus catappifolia. Na estrutura de inserção, 529 indivíduos não apresentaram nenhuma estrutura em seu entorno, 207 foram alocados em grama, 30 no cimento, 3 no asfalto, 3 em vaso e 3 em pneu (figura 2D).

\section{DISCUSSÃO}

\section{Análise quantitativa}

O levantamento total permitiu caracterizar as espécies de plantas existentes e assim estabelecer um diagnóstico atual da vegetação, o que posteriormente poderá servir para embasar o manejo e a manutenção 
da área pelos órgãos responsáveis (MUNEROLI et al., 2010). O número total de indivíduos e de famílias botânicas encontrados foi elevado, podendo-se afirmar que na avenida há uma significativa variedade de espécies. Em trabalho realizado na avenida Frei Sarafim no Piauí, foram inventariados 308 indivíduos, pertencentes a 8 famílias botânicas (MORAES et al., 2016) e 111 indivíduos pertencentes a 16 famílias botânicas em Jequití - Minas Gerais (SANTOS et al., 2019) locais com número de espécies inferior.

As famílias mais representativas foram Fabaceae, Bignoniaceae, Rubiaceae e Arecaceae. A família Fabaceae e Arecaceae são geralmente bem representadas nos trabalhos que envolvem a arborização urbana nas cidades brasileiras (AQUA et al., 2014; SILVA et al., 2018; SOUSA et al., 2019), podendo a sua utilização estar relacionada ao elevado número de espécies pertencentes a este táxon, a sua ampla distribuição geográfica e potencial paisagístico (SILVA et al. 2018) ou ainda a sua capacidade adaptativa e sobrevivência em ambientes diversos (RODRIGUES et. al., 2014). As famílias Bignoniaceae e Rubiaceae também são bem utilizadas na arborização sendo bem representadas com a utilização dos gêneros Handroanthus e Ixora pelo potencial ornamental.

Na avenida 52\% das espécies são nativas e $48 \%$ são exóticas, dentre as nativas, as espécies com maior número de indivíduos foram ipê amarelo e oiti e para as exóticas foram ixora vermelha e mangueira. Resultado similar foi encontrado com $51,5 \%$ de espécies nativas e $48,4 \%$ de exóticas, sendo as espécies nativas mais comuns o ipê e oiti e espécie exótica a ixora (SOUSA et al., 2019).

As espécies exóticas tem como pontos positivos suas características paisagísticas, floradas perfumadas e porte adequado, no entanto, como pontos negativos tem-se a falta de representatividade da vegetação local, a competição com as nativas e a toxicidade de algumas espécies para a fauna local (ALENCAR et al., 2014; PERIOTTO, et al., 2016; SOUSA et al., 2019). As espécies exóticas não devem ser eliminadas do ambiente urbano, no entanto, devem ser empregadas com a finalidade de complementar as espécies nativas na arborização urbana (SJÖMAN et al., 2016)

Com o intuito de se obter um planejamento eficaz, minimizando a propagação de doenças além de formar um espaço mais atrativo a fauna, é importante manter a diversidade de espécies, sendo ideal que cada espécie presente em determinada área não ultrapasse 15\% do total de indivíduos (BRIANEZI et al., 2013; KERN et al., 2013). Na área de estudo nenhuma das 50 espécies encontradas obtiveram FR superior a 15\%, estando dentro do recomendado.

A predominância de apenas três (3) espécies Handroanthus serratifolius, Mangifera indica e Ixora chinensis nesta Avenida pode ser considerada um fato comum, mas não adequado para a vegetação de áreas urbanas (STRANGHETTI et al., 2000). Desta forma, as espécies acima citadas apresentaram as maiores FA e correspondem a $53,4 \%$ do censo da avenida, representando mais da metade da maioria dos indivíduos do local.

Recomenda-se que uma espécie em uma paisagem urbana não exceda mais que $10 \%$ da densidade, no entanto, verificou-se que Handroanthus serratifolius, Mangifera indica, Agave angustifolia e Ixora chinensis estão acima do percentual indicado, proporcionando uma homogeneidade da vegetação que poderá gerar risco de ocorrência de pragas e doenças, ocasionando até em uma possível dizimação das 
espécies (SILVA et al., 2018).

Apesar da Mangifera indica ter sido empregada significativamente na avenida, esta espécie não é indicada para vias públicas ou calçadas, por apresentar um sistema radicular muito agressivo e frutos relativamente grandes, sendo perceptível que os plantios de espécies frutíferas, em geral, correspondem a ações não planejadas, feita de forma espontânea pela população local (ALMEIDA et al., 2010).

Já Handroanthus serratifolius é muito utilizado na arborização pelo seu belo efeito paisagístico proporcionado pela sua intensa floração, pela sua baixa exigência de podas, pelo sistema radicular pivotante e pouco ramificado e resistência à poluição urbana (SILVA et al., 2007), no entanto, deve-se ter atenção com a acentuada queda de folhas na época da florada ocasionando entupimento de bueiros, sujando as ruas e perdendo também a função de sombreamento. Apesar do número reduzido de indivíduos de Licania tomentosa - oiti e Ficus catappifolia - figueira, atribui-se a utilização dessas espécies na arborização por proporcionarem sombra durante o ano inteiro devido as suas copas frondosas e pelo rápido crescimento (SILVA et al., 2018; SOUSA et al., 2019).

$\mathrm{Na}$ arborização urbana o porte dos componentes arbóreos pode ser classificado em três categorias, pequeno porte - para indivíduos com altura $<5 \mathrm{~m}$; médio porte - para indivíduos com altura $\geq 5$ e $<10 \mathrm{~m}$, e grande porte - para indivíduos com altura $\geq 10 \mathrm{~m}$ (GONÇALVES et al., 2004). Nesse contexto, é indicado para o canteiro central de avenidas, espécies de pequeno ou médio porte e para as calçadas, somente de pequeno porte (PAIVA, 2000). Além de não ser recomendado arborizar ruas estreitas com menos de $7 \mathrm{~m}$ largura. Quando estas forem largas, deve-se considerar ainda a largura das calçadas de forma a definir o porte da árvore a ser utilizado (RESENDE, 2011).

De acordo com o levantamento de dados do inventário e com o contexto de classificação de porte arbóreo, foi observado na avenida que os indivíduos arbóreos obtiveram alturas adequadas no canteiro central, onde a maior altura média estimada foi de 8,56 m, apesar de alguns indivíduos (76) apresentarem potencialidade de contato com a fiação elétrica. No entanto, este parâmetro sozinho não representa a adequação do indivíduo ao local de inserção, no qual, deve-se também ser observado o conjunto de caracteres como o DAP, comprimento da copa e superficialidade das raízes.

Analisando a altura e o comprimento da copa de indivíduos para serem inseridos nas vias de rolamento, deve-se priorizar espécies que tenham como característica sua primeira bifurcação a $2 \mathrm{~m}$ de altura do solo, pois caso não seja seguido este parâmetro poderá resultar em problemas na implementação no meio urbano devido ao fluxo de pessoas que irão transitar, sendo necessário manutenção através podas (ZAMPRONI et al., 2018) e o fuste deve ter o mínimo de tortuosidade para não prejudicar a passagem de pedestres e de veículos nas vias (TOSCAN et al., 2010).

\section{Análise qualitativa}

Com relação a viabilidade $84,9 \%$ dos indivíduos apresentaram algum tipo de dano, mesmo sendo considerado leve, este parâmetro requer atenção pois sem a manutenção adequada desses indivíduos esses danos podem se agravar ao longo do tempo. Quanto à fitossanidade dos indivíduos avaliados, apesar de 56\% 
não apresentarem nenhum grau de ataque de agentes xilófagos ou fungos em sua estrutura, os $44 \%$ restantes se dividiram em alteração leve, moderada e grave quanto a incidência e ação de fungos e formigas tendo destaque para a alteração em nível moderado ocorrente em 65\% dos 292 indivíduos atacados.

Analisando a fitossanidade, Sousa et al. (2019), encontraram que $63,6 \%$ dos indivíduos estavam em boas condições e $38,4 \%$ encontravam-se em condições ruins. A longevidade e integridade das plantas pode ser interferida pelos danos causados por insetos sugadores e cupins. Esses problemas são recorrentes em ambientes urbanos, recomendando-se a substituição de alguns indivíduos (ROLON et al., 2018; SOUSA et al., 2019).

Esse processo é resultante do manejo inadequado ou inexistente da arborização da avenida, podendo ser proveniente de podas mal executadas onde a área exposta do corte se torna foco de entrada e desenvolvimento de pragas e doenças, que com o decorrer do tempo, poderão se alastrar para outras partes, levando os indivíduos a morte prematura (GUIA et al., 2008).

A qualidade do fuste é fundamental em um planejamento urbano, podendo a tortuosidade no fuste de um indivíduo vegetativo desestabilizar sua a estrutura física, levando ao seu tombamento, pois as inclinações somadas aos ventos fortes podem apresentar condições favoráveis à queda (SCHALLENBERGER et al., 2013). Na área de estudo a maior parte dos indivíduos dos hábitos árvore e arvoreta apresentam algum grau de tortuosidade, o que pode acarretar em transtornos a médio e longo prazo.

Analisando a copa dos indivíduos pertencentes ao gênero Handroanthus, que obteve maior incidência de espécimes (192) na avenida, são árvores com copa em maioria rala e com flores vistosas com um bonito efeito estético, no entanto, o hábito caducifólio é uma característica importante desse gênero, onde a queda natural dos folíolos durante a época de floração acarreta na perda temporária do benefício de sombreamento (LORENZI, 2008).

Para a alocação de espécies do gênero Handroanthus na arborização urbana é importante levar em conta seu caractere caducifólio e o objetivo para a qual a espécie será plantada, quando puramente estético é uma opção relevante para inserção em canteiros centrais e praças, como observado na área de estudo onde apenas 2 indivíduos do gênero estão inseridos em calçadas e os demais (190) espalhados ao longo do avenida nos canteiros centrais.

Observou-se que os demais indivíduos apresentaram em maioria densidade moderada de copa (249) e alta densidade (175) o que representa um bom indicativo de sombreamento na avenida, pois o diâmetro e densidade de uma copa são responsáveis por um efeito benéfico do sombreamento em cidades (OLIVEIRA et al., 2013). A potencialidade de alguns indivíduos com a fiação telefônica e elétrica não apresentou em sua maioria contato, $81,31 \%$ foi observado como ausente. A deformação das copas inicia-se pelo conflito direto ou potencial com a fiação, indicando a necessidade de podas para a redução do porte dos indivíduos (BARROS et al., 2010)

Para os locais que existem indivíduos sob a fiação, cujas copas apresentaram contato ou potencialidade de contato, a possibilidade de aumentar ocorrência de conflitos entre as árvores e vias públicas com a fiação elétrica e telefônica são mais significativas, ocasionadas pela falta de planejamento 
(ALMEIDA et al., 2010). Preferencialmente espécies de pequeno porte, crescimento lento e facilidade na condução da copa devem ser implantadas sob rede de energia elétrica (CEMIG, 2011; SANTOS et al., 2019).

Considerando o local de inserção, como as calçadas, canteiros e praças, as espécies conhecidas como figueiras em geral, são indivíduos arbóreos não indicados para plantio nesses locais. Alguns indivíduos do gênero Ficus geralmente ocasionam danos à estrutura do local inserido pela agressividade da superficialidade das suas raízes (SVMA, 2017). Embora a ocorrência do gênero Ficus na Avenida Mendonça Furtado ter sido pouco expressiva (12), os indivíduos do gênero demostraram danos graves nas estruturas em seu entorno, não sendo possível reparação sem que exista a remoção dos mesmos.

$\mathrm{Na}$ avenida foi constatado que em sua maior parte, a vegetação do local encontra-se com a terra exposta, o que não é recomendado. Ambiente onde o solo é exposto, sem cobertura de concreto ou muito próximo de construções podem oferecer condições para formação de raízes superficiais, podendo ocasionar acidentes, danificar muros, calçadas e construções (PATRICIO, 2017).

\section{CONCLUSÕES}

Em toda a extensão da avenida foram inventariadas 50 espécies, indicando uma elevada diversidade na arborização desta via pública, porém, a distribuição dessas ocorreu de maneira desigual, com a prevalência das espécies de Mangifera indica e o Handroanthus serratifolius, ocasionando uma homogeneidade na avenida e propiciando uma maior vulnerabilidade a pragas e doenças. Os principais conflitos encontrados provavelmente foram gerados pelos plantios aleatórios e sem padrões técnicos realizados por ação da própria população, intensificando os problemas na arborização da via.

Para o sombreamento de vias, as espécies Holocalyx balansae e Licania tomentosa podem ser recomendadas, já para o embelezamento paisagístico a espécie Handroathus serratifolius pode ser utilizada. Recomendações que são baseadas na expressividade das cores das flores, densidade da copa, fitossanidade e ausência de danos nas estruturas de inserção, como os canteiros centrais, calçadas ou praças, vale ressaltar que destas, duas estão presentes na avenida. Por fim, cabe ressaltar que cada município possui uma identidade quanto à realidade cultural, climática e pedológica, de forma que estes aspectos devem sempre ser considerados, em um processo de seleção dos indivíduos mais bem indicados para cada situação.

\section{REFERÊNCIAS}

ALENCAR, L. S.; SOUTO, P. C.; MOREIRA, F. T. A.; SOUTO, J. S.; BORGES, C. H. A.. Inventário quali-quantitativo da arborização urbana em São João do Rio do Peixe - PB. Agropecuária Científica no Semiárido, Campina Grande, v.10, n.2, p.117-124, 2014. DOI: http://dx.doi.org/10.30969/acsa.v10i2.554

ALMEIDA, D. N.; NETO, R. M. R.. Análise da arborização urbana de duas cidades da região norte do estado de Mato Grosso. Revista Árvore, Viçosa, v.34, n.5, p.899-906, 2010. DOI: http://dx.doi.org/10.1590/S0100-67622010000500015

AQUA, M. D.; MULLER, N. T. G.. Diagnóstico da arborização urbana de duas vias na cidade de Santa Rosa - RS. Revista da Sociedade Brasileira de Arborização Urbana, Piracicaba, v.9, n.3, p.141-155, 2014.

BARROS, E. F. S.; GUILHERME, A. G.; CARVALHO, R. S.. Arborização urbana em quadras de diferentes padrões construtivos na cidade de Jataí. Revista Árvore, Viçosa, v.34, n.2, p.287-295, 2010. DOI: http://dx.doi.org/10.5380/revsbau.v9i3.63147

BRIANEZI, D.; JACOVINE, L. A. G.; GONÇALVES, W.; ROCHA, S. J. S. S.. Avaliação da Arborização no campus-sede da Universidade Federal de Viçosa. Revista da Sociedade Brasileira de Arborização Urbana, Piracicaba, v.8, n.4, 2013. 
CECCHETTO, C. T; CHRISTMANN, S. S.. Arborização Urbana: importância e benefícios no planejamento ambiental das cidades. In: SEMINÁRIO INTERNACIONAL DE EDUCAÇÃO NO MERCOSUL, 16. Anais. Cruz Alta: UNICRUZ, 2014.

COLETTO, E. P.; MULLER, N. G.; WOLSKI, S. S.. Diagnóstico da arborização das vias públicas do município de Sete de Setembro - RS. Revista da Sociedade Brasileira de Arborização Urbana, Piracicaba, v.3, n.2, p.110-122, 2008. DOI: http://dx.doi.org/10.5380/revsbau.v3i2.66353

CEMIG. Companhia Energética de Minas Gerais. Manual de arborização. Belo Horizonte: CEMIG, 2011.

DOURADO, F. F.; ANDRADE, M. M. N.; CANEIRO, C. C. Geração de Mapa de riscos em Santarém-PA: abordagem baseada na lógica Fuzzy. Geociências, São Paulo, v.36, n.3, 2017.

GUIA, G. H.; ALBRETCH, J. M.; SOARES, T. S.; TITON, M. Avaliação Qualitativa das Espécies Arbóreas do Parque Antônio Pires de Campos em Cuiabá-MT. Revista da Sociedade Brasileira de Arborização Urbana, Piracicaba, v.3, n.3, p.36-46, 2008. DOI:

http://dx.doi.org/10.5380/revsbau.v3i3.66362

GONÇALVES, T. P.; SANTOS Jr, A. R.. Projeto Construindo a Ecocidadania- percepções acercadas atividades de Educação Ambiental. In: CONGRESSO BRASILEIRO DE GESTÃO AMBIENTAL, 3. Anais. Goiânia: IBEAS, 2012.

IBGE. Instituto Brasileiro de Geografia e Estatística. Banco de Dados. Rio de Janeiro: IBGE, 2019.

KERN, D. I.; SCHMITZ, A. K.. Arborização de Vinte quarteirões amostrados na região central de Santa Cruz do Sul. Revista da Sociedade Brasileira de Arborização Urbana, Piracicaba, v.8, n.3, 2013. DOI:

http://dx.doi.org/10.5380/revsbau.v8i3.66435

LORENZI, H.. Árvores Brasileiras: manual de identificação e cultivo de plantas arbóreas do Brasil. 5 ed. Nova Odessa: Instituto Plantarum, 2008

MELO, R. R.; LIRA FILHO, J. A.; RODOLFO JÚNIOR, F. Diagnóstico quantitativo e qualitativo da arborização urbana no bairro Bivar Olinto, Patos, Paraíba. Revista da Sociedade Brasileira de Arborização Urbana, Piracicaba, v.2, n.1, 2007. DOI: http://dx.doi.org/10.5380/revsbau.v2i1.66241

MORAES, L. A.; ALMEIDA, F. M. N.; ARAÚJO, M. F. V.. Arborização do canteiro central da avenida Frei Sarafim, Teresina-PI: análise quali-quantitativa. Revista Equador, Teresina, v.5, n.3, p.78-98, 2016.

MUNEROLI, C. C.; MASCARÓ, J. J.. Arborização Urbana: uso de Espécies Nativas na Captura do Carbono Atmosférico. Revista da Sociedade Brasileira de Arborização Urbana, Piracicaba, v.4, n.1, p.160-182, 2010. DOI: http://dx.doi.org/10.5380/revsbau.v5i1.66258

OLIVEIRA, A. S.; SANCHES, L.; MUSIS, C. R.; NOGUEIRA, M. C. J.. Benefícios da arborização em praças urbanas - o caso de Cuiabá/MT. Revista Eletrônica em Gestão, Educação e Tecnologia Ambiental, Santa Maria, v.9, n.9, p.1900-1915, 2013. DOI: $\underline{\text { http://dx.doi.org/10.5902/223611707695 }}$
PAIVA, H. N.. Seleção de espécies para Arborização. Revista Ação Ambiental, Viçosa, v.2, n.9, p.14-16, 2000.

PARRY, M. M.; SILVA, M. M.; SENA, I. S.; OLIVEIRA, F. P. M. Composição Florística da Arborização da Cidade de Altamira, Pará. Revista da Sociedade Brasileira de Arborização Urbana, Piracicaba, v.7, n.1, p. 143-158, 2012. DOI: http://dx.doi.org/10.5380/revsbau.v7i1.66550

PATRICIO, P. P. M.. Florística e diagnóstico da arborização da Universidade Federal de Mato Grosso, campus Cuiabá. Dissertação (Mestrado em Ciências Florestais e Ambientais) Universidade Federal de Mato Grosso, Cuiabá, 2017.

PERIOTTO, F.; PITUCO, M. M.; HELMANN, A. C.; SANTOS, T. O.; BORTOLOTTI, S. L.. Análise da arborização urbana no município de Medianeira, Paraná. Revista da Sociedade Brasileira de Arborização Urbana, Piracicaba, v.11, n.2, p.59-74, 2016. DOI:

http://dx.doi.org/10.5380/revsbau.v11i2.63428

RANSAN, J.; FIGUEREDO, A. M. B.. A Arborização Urbana no Município de Chapecó e a importância do Plantio de Espécies condizentes ao Local. Revista Tecnológica, Santa Catarina, v.3, n.2, p.15-33, 2015

RESENDE, O. M. Arborização Urbana: Barbacena. Monografia - (Bacharelado em Geografia e Meio Ambiente). Universidade Presidente Carlos, Piracicaba, 2011.

RODRIGUES, J. S.; BRANCO, J. C.; MELO, J. I. M.. Flora de um inselberg na mesorregião agreste do estado da ParaíbaBrasil. Polibotânica, Colonia Santo Tomás, n.37, p.47-61, 2014.

ROLON, M. S.; SIQUEIRA, M. V. B. M.. Diagnóstico arbóreo comparativo em bairros de Lençóis Paulista - SP. Revista da Sociedade Brasileira de Arborização Urbana, Piracicaba, v.13, n.1, p.43-56, 2018. DOI: http://dx.doi.org/10.5380/revsbau.v13i1.63598

ROMANI, G. N.; GIMENES, R.; M. T.; PIVETTA, K. F. L.; BATISTA, G. S.. Análise Quali-Quantitativa da Arborização na praça XV de Novembro em Ribeirão Preto - SP, Brasil. Revista Árvore, Viçosa, v.36, n.3, p.479-487, 2012. DOI: http://dx.doi.org/10.1590/S0100-67622012000300010

SANTOS, C. A.; SERRÃO, E. A. O.; GONÇALVES, L. J. M.; WANZALER, R. T. S.; LIMA, A. M. M.. Zoneamento da Distribuição da Precipitação Pluviométrica na Bacia Hidrográfica do Rio Tapajós. Centro Científico Conhecer, Goiânia, v.10, n. 18, p.3092-3106, 2014

SANTOS, C. Z. A.; FERREIRA, R. A.; SANTOS, L. R.; SANTOS, L. I.; GOMES, S. H.; GRAÇA, D. A. S.. Análise Qualitativa Da Arborização Urbana De 25 Vias Públicas Da Cidade De Aracaju-SE. Santa Maria, RS. Ciência Florestal, v.25, n.3, p.751-763, 2015. DOI: http://dx.doi.org/10.5902/1980509819678

SANTOS, G. R.; FONSECA, R. S.; GONÇALVES, C. B.. Arborização urbana em Jequitaí - MG: atributos funcionais e diversidade. Revista da Sociedade Brasileira de Arborização Urbana, Curitiba, v.14, n.1, p.01-13, 2019. DOI: http://dx.doi.org/10.5380/revsbau.v14i1.65444 
Arborização na Região Central do Município de Mangueirinha-PA. Revista da Sociedade Brasileira de Arborização Urbana, Piracicaba, v.8, n.1, 2013. DOI: http://dx.doi.org/10.5380/revsbau.v8i1.66350

SVMA. Secretaria do Verde de Meio Ambiente. Prefeitura de Mogi das Cruzes. Cartilha de Arborização Urbana. Mogi das Cruzes, 2017.

SILVA, L. A.; SOUSA, C. S.; PARRY, M. M.; HERRERA, R. C.; OLIVEIRA, F. P. M.; PARRY, S. M.. Diagnóstico da arborização urbana da cidade de Vitória do Xingu, Pará, Brasil. Revista da Sociedade Brasileira de Arborização Urbana, Piracicaba, v.13, n.1, p.57-72, 2018. DOI:

http://dx.doi.org/10.5380/revsbau.v13i1.63622

SILVA, L. M.; MOCCELLIN, R.; WEISSHEIMER, D. I.; ZBORALSK, A. R.; FONSECA, L.; RODIGHIERO, D. A.. Inventário e sugestões para arborização em via pública de Pato Branco/PR. Revista da Sociedade Brasileira de Arborização Urbana, Piracicaba, v.2, n.1, p.100-108, 2007. DOI: http://dx.doi.org/10.5380/revsbau.v2i1.66249

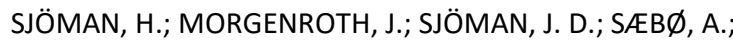
KOWARIKE, I.. Diversification of the urban forest-Can we afford to exclude exotic tree species?. Urban Forestry \& Urban Greening, Amsterdam, v.18, n.1, p.237-241, 2016. DOI: https://doi.org/10.1016/j.ufug.2016.06.011

SOUSA, L. A.; CAJAIBA, R. L.; MARTINS, J. S. C.; COLÁCIO, D. S.; SOUSA, E. S.; PEREIRA, K. S.. Levantamento quali- quantitativo da arborização urbana no município de Buriticupu, MA. Revista da Sociedade Brasileira de Arborização Urbana, Curitiba, v.14, n.1, p.42-52, 2019. DOI: http://dx.doi.org/10.5380/revsbau.v14i1.65372

STRANGHETTI, V.; SILVA, Z. A. V.. Diagnóstico da Arborização das vias Públicas do Município de Uchôa - SP. Revista da Sociedade Brasileira de Arborização Urbana, Piracicaba, v.5, n.2, p.124-138, 2010. DOI:

http://dx.doi.org/10.5380/revsbau.v5i2.66274

TOSCAN, M. A. G.; RICKLI, H. C.; BARTINICK, D.; SANTOS, D. S.; ROSSA, D.. Inventário e Análise da Arborização do Bairro Vila Yolanda, do município de Foz de Iguaçu-PA. Revista da Sociedade Brasileira de Arborização Urbana, Piracicaba, v.5, n.3, p.165-184, 2010. DOI:

http://dx.doi.org/10.5380/revsbau.v5i3.66311

VELOPE-FILIK, A.; SILVA, L. F.; LIMA, A. M. L. P.. Avaliação da Arborização de Ruas do Bairro de São Dimas na Cidade de Priacicaba/SP através de Parâmetros Qualitativos. Revista da Sociedade Brasileira de Arborização Urbana, Piracicaba, v.2, n.1, p.1-10, 2007. DOI:

http://dx.doi.org/10.5380/revsbau.v2i1.66234

ZAMPRONI, K.; BIONDI, D.; MARIA, T. R. B. C.; LOUVEIRA, F. F.. Diagnóstico quali-quantitativo da arborização viária de Bonito, Mato Grosso do Sul. Floresta, Curitiba, v.48, n.2, p.235-244, 2018

DOI: http://dx.doi.org/10.5380/rf.v48i2.55531 